\title{
CONTRIBUTION TO THE MODELLING OF THE ICE ACCRETION PROCESS: ICE DENSITY VARIATION WITH
} THE IMPACTED SURFACE ANGLE

\author{
by \\ M. Bain and J. F. Gayet \\ (Laboratoire Associé de Météorologie Physique, Université de Clermont II, B.P.45, \\ 63170 Aubière, France)
}

\begin{abstract}
Icing measurements were carried out in natural winter clouds with an instrumented wind tunnel set up at the suminit of Puy de Dôme (1 $500 \mathrm{~m} \mathrm{a.s.1.).}$ The microphysical data (1 iquid water content, droplet spectra) were obtained by using the particle measuring system PMS ASSP 100. The ice density was measured on a rotating cylinder and the ice deposit of the cross-section was photographed on a fixed cylinder. The density measurements ranged from 300 to $900 \mathrm{~kg} \mathrm{in}^{-3}$ during the experiment and are in agreement with Macklin's results (1962). The profile of the ice deposit is compared to the profile predicted by the model of Lozowski and others (1979), which considers a fixed density.

We propose to improve this model by taking into account the variation of ice density with the angle of impact on the cylinder. This calculation is based on Macklin's results and on the determination of the local impact speed by using the result of Langmuir and Blodgett (1960). The variation of ice density with the angle depends on various paraineters: pressure, temperature, air speed, liquid water content, and, especially, the droplet distribution. The improvenent is not sufficient to explain some observed profiles; this may be attributed to the fact that the model is not time-dependent.
\end{abstract}

\section{INTRODUCTION}

In winter 1981, icing measurements were carried out in an instrumented wind tunnel set up at the observatoire du Puy de Dôme, which is located on the

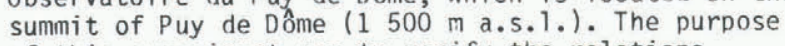
of this experiment was to verify the relations between the characteristics of ice accretion on cylinders and meteorological parameters such as air temperature, air speed, liquid water content, and droplet diameter. A numerical model (Lozowski and others 1979) was used to simulate the profiles of the ice cap.

The purpose of this paper is to compare the observed and the predicted profiles and to attempt to explain the differences between them in order to improve the model.

\section{EXPERIMENTAL PROCEDURE}

The open wind tunnel was used when the observatory was surrounded by clouds. The inflow of cloudy air was sampled in a cross-sectional area of $200 \times 300 \mathrm{~mm}$. The air speed ranged from 17 to $25 \mathrm{~m} \mathrm{~s}^{-1}$. The following probes were set up: a PMS* ASSP-100 for the measurement of cloud droplet spectra $(3 \leqslant d \leqslant 45 \mu \mathrm{m})$, a PMS $2 \mathrm{D}-\mathrm{C}$ providing particle images with dimensions from 25 to $800 \mu \mathrm{m}$, two icing cylinders $(22.5 \mathrm{~mm}$ diameter), one fixed and the other rotating at $15 \mathrm{rpm}$, and a thermometer and a Pitot tube for the measurements of air temperature and velocity, respectively. The microphysical data were recorded at a frequency of $1 \mathrm{~Hz}$.

When the accretion on a cylinder had grown to a noticeable size under quasi-homogeneous cloud microstructure (indicated on a real-time display) the wind tunnel was stopped. The ice density was deduced from measurements of the mass and thickness of the deposit on the rotating cylinder, and the crosssection of the ice profile on the fixed cylinder was photographed. During the whole experiment, which included 45 tests, various meteorological conditions were encountered. The outside temperature ranged from -2 to $-9^{\circ} \mathrm{C}$, the cloud liquid water content and median volume diameter, calculated from the ASSP data, ranged from 0.05 to $0.30 \mathrm{~g} \mathrm{~m}^{-3}$ and from 7 to $23 \mu \mathrm{m}$ respectively. The ice water content was evaluated from the $2 \mathrm{D}-\mathrm{C}$ images and varied from zero to $0.1 \mathrm{~g} \mathrm{~m}^{-3}$.

3. COMPARISON BETWEEN THE EXPERIMENT AND THE MONEL OF LOZOWSKI AND OTHERS (1979)

This model requires, as input parameters, the values of the cylinder diameter, the air speed, the temperature, the liquid water content, the ice particle content and the size distribution of the cloud droplets. The steady-state heat-balance equation is solved with a $5^{\circ}$ angle intervals around the cylinder surface, and the model deduces the local equilibrium surface temperature, the ice fraction of the impinging and run-back water substance, and the local rate of icing. The unfrozen liquid, with any entrained

* PMS: Probe manufactured by Particle Measuring Systems, Boulder, Colorado, IJ.S.A. 
ice particles, is allowed to run back from one $5^{\circ}$ sector to the next, starting from the stagnation line and participating in the local heat exchange. The diffusivity of heat is neglected in the cylinder and in the ice deposit. Any unfrozen water at a polar angle of $90^{\circ}$ is assumed to be shed into the air stream.

Under mixed accretion conditions, the model assumes an ice-sticking efficiency value based on thermodynamic considerations only, such that ice particles can stick to a wet surface, but not to a dry one. The thickness of the ice deposit is deduced from the evaluation of the ice growth flux in each sector, by using the formula

$$
h=R \cdot \Delta t / \rho \cdot \cos \theta \text {, }
$$

where $R$ is the ice growth flux, $\Delta t$ the time duration of the simulation, $\rho$ the ice density, and $\theta$ the angle.

For all of the present wind tunnel tests, the deposit grew under dry conditions and the profiles predicted by the model of Lozowski and others (1979) have an elliptical shape. Two examples, (a) and (b), are compared in Figure 1. The thick curves correspond

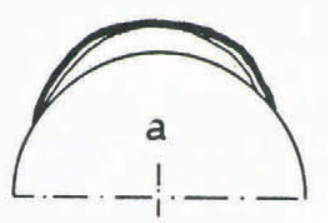

$$
\begin{aligned}
& P=850 \mathrm{mb}, T=-4^{\circ} \mathrm{C} \\
& U=23 \mathrm{~m} \cdot \bar{s}^{-1}, L W C=0.12 \mathrm{gm}^{-3} \\
& D V=13 \mu \mathrm{m}, \rho=645 \mathrm{~kg} \mathrm{~m}
\end{aligned}
$$$$
\Delta t=1560 \mathrm{~s}
$$

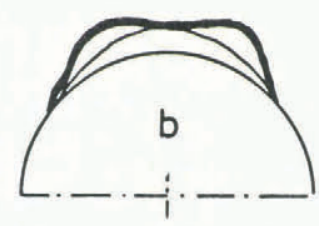

$$
\begin{aligned}
& P=850 \mathrm{mb}, T=-5^{\circ} \mathrm{C} \\
& U=22 \mathrm{~m} \cdot \mathrm{s}^{-1}, L W C=0.10 \mathrm{gm}^{-3} \\
& D V=10 \mu \mathrm{m}, \rho=492 \mathrm{~kg} \cdot \mathrm{m}^{-3}
\end{aligned}
$$$$
\Delta t=2160 \mathrm{~s}
$$

Fig.1. Comparison between two observed (thick line) and predicted (thin line) profiles.

to the observed profiles on the fixed cylinder and the thin curves to the predicted profiles*. The ineteorological characteristics (pressure $P$, temperature $T$, air speed $U$, liquid water content LWC, median volume diameter $D_{V}$, ice density $\rho$, and experimental duration $(\Delta t)$ are also shown. In example $(a)$, a good agreement occurs between the two profiles whereas in (b) there is a noticeable difference between them. In this latter case, the observed profile presents a flat front surface in contrast to the elliptical profile that is predicted. It may be noticed that the time duration of the simulation is higher than in the previous case.

Two reasons for this difference can be suggested: (i) the ice density used in the model is considered to be constant for the whole deposit, and equal to $890 \mathrm{~kg} \mathrm{~m}^{-3}$, while the measured density varies from about 300 to $900 \mathrm{~kg} \mathrm{~m}^{-3}$, and (ii) the model is not time-dependent and does not take into account the change of the collection efficiency with the time evolution of the profile through the modification of the flow pattern. This second point is not fully considered in this work, but is under investigation. We focus our attention primarily on the density variation with the cylinder angle.

* The thickness of ice is plotted in the direction parallel to the free air-stream direction; the heat-transfer coefficient for a rough surface is assumed.
4. FORMULATION OF THE DENSITY VARIATION WITH THE CYLINDER ANGLE

4.1. Experimental results on the ice density on the rotating cylinder.

Our density measurements from the rotating cylinder are shown in Figure 2 against the ratio $\left(-r V_{0} / T_{s}\right)$, as suggested by Macklin (1962), where $r$ is the median volume radius of the cloud droplet spectra, $V_{0}$ the speed of impact of the droplet on the stagnation line, and $T_{s}$ the mean temperature of the riming cylinder. The impact speed on the stagnation line $V_{0}$ is obtained from the curves of Langmuir and Blodgett (1960). The surface temperature is calculated from the heat balance equation at the riming surface of the cylinder.

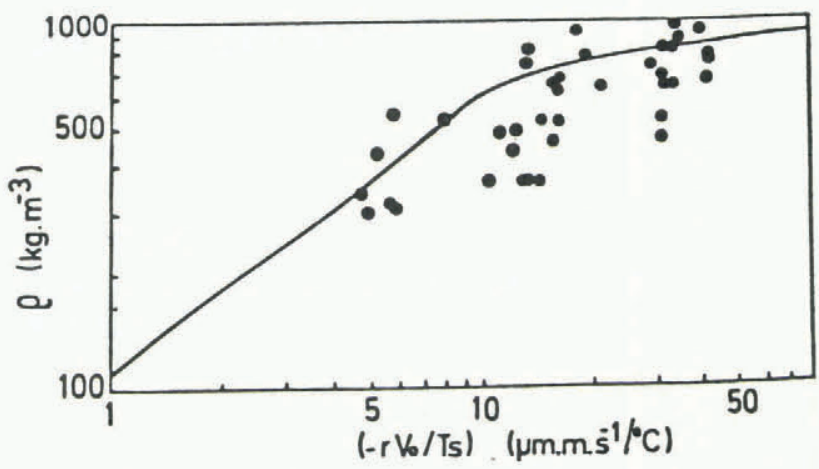

Fig.2. Measured ice densities on the rotating cylinder versus the ratio $\left(-r V_{0} T_{s}\right)$ (see text) and the curve of Macklin (1962).

Figure 2 also shows the curve corresponding to the best fit of the data set obtained by Macklin (1962). Despite the fact that our data are obtained with a higher air speed and a larger cylinder diameter than those used by Macklin ( $25 \mathrm{~m} \mathrm{~s}^{-1}$ against $12 \mathrm{~m} \mathrm{~s}^{-1}$ and $22.5 \mathrm{~mm}$ against $14.3 \mathrm{~mm}$, respectively), our density measurements are in rather good agreement with Macklin's curve. The scattering of our data points (which is of the same order as that of Macklin) is mainly due to the experimental errors (for example $\approx 20 \%$ on the ice density measurements). For the parameterization of the variation of the ice density, we use the formulation suggested by Macklin when $\left(-r V_{0} / T_{S}\right)<10$ :

$$
\rho=110\left(-r V_{0} / T_{s}\right)^{0.76} \mathrm{~kg} \mathrm{~m}^{-3} \text {. }
$$

For $\left(-r V_{0} / T_{S}\right)$ ranging from 10 to 60 , we propose the following expression:

$$
\rho=10^{3}\left(-r V_{0} / T_{s}\right) /\left(-r V_{0} / T_{s}+5.61\right) \mathrm{kg} \mathrm{m}^{-3},
$$

which approximates Macklin's curve to an accuracy better than $7 \%$. This formula is chosen due to the finite density limit when the ratio $\left(-r V_{0} / T_{S}\right)$ reaches large values. We take a constant value of $\rho=917 \mathrm{~kg} \mathrm{~m}^{-3}$ for $\left(-r V_{0} / T_{s}\right)>60$.

4.2. Determination of the 1ocal impact speed and the local surface temperature versus the angle $\theta$ on the fixed cylinder

In order to express the local density of the ice on the fixed cylinder, we assume that the physical process of the ice accretion is the same on a rotating or a fixed cylinder. Then the local ice density $\rho(\theta)$ is assumed to be a function of:

$$
\left(\frac{-r v_{r}(\theta)}{T_{S}(\theta)}\right) \text {, }
$$

where the quantity $r V_{r}(\theta)$ is interpreted as being a measure of the local force with which the droplets 


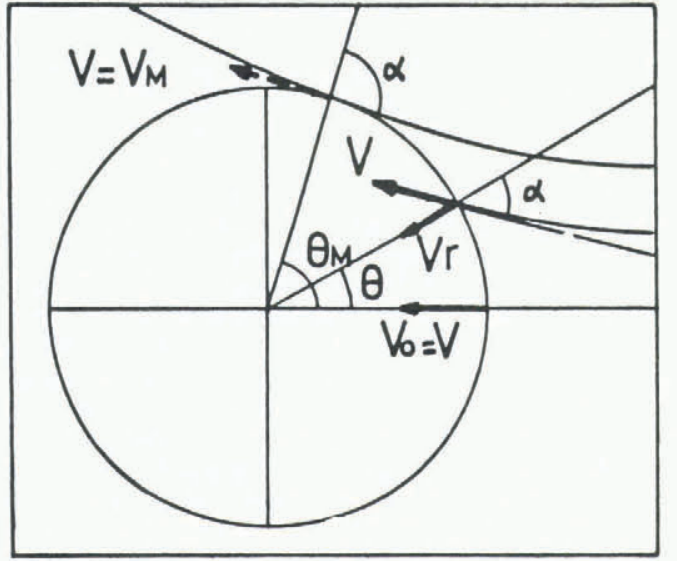

Fig.3. Droplet trajectories with the corresponding droplet speed and local impact speed (radial component).

are packed together, and $T_{s}(\theta)$ is the local surface temperature which governs the local freezing rate.

The above formulae are used together with Ts $(\theta)$, which is the surface temperature of the angle $\theta$ determined by a local heat-energy balance, as proposed by Lozowski and others (1979), and $V_{r}(\theta)$, which is the local impact speed taken as the radial component (perpendicular to the surface) of the droplet speed calculated at the angle $\Theta$. To determine $V_{r}(\theta)$ we proceed as follows: (a) we obtain a relationship for the impact speed on the stagnation line $V_{0}$ from the curves of Langmuir and Blodgett $(1960)$, (b) we calculate the droplet speed $V(\theta)$, assuming that this parameter is a linear function of $\cos (\theta)$ from the value $V_{0}$ at $\theta=0^{\circ}$ to $V_{M}=1.05 \mathrm{U}$ at $\theta=\theta_{M}$, with $U$ the true air speed in the undisturbed flow (froin Langmuir and Blodgett 1960), and $(c)$ we express the local impact speed as

$V_{r}(\theta)=V(\theta) \cos (\alpha)$, where $\alpha$ is the angle between the radius direction and the tangent to the trajectory of the droplet at the point of impact, as shown in Figure 3. Three possible droplet trajectories are plotted: for $\theta=0^{\circ}$, for any $\theta$, and for $\theta=\theta_{M}$, with the corresponding impact speed: $V_{r}(0)=V_{0}$, $V_{r}(\theta)=V(\theta) \cos (\alpha)$, and $V_{r}\left(\theta_{M}\right)=0$.

Figure 4 shows the local impact speed $v_{r}$, determined by the three steps described above, plotted against the angle $\theta$. The parameters used in the calculation are pressure $P$ ( 850 mbar), air temperature $T\left(-10^{\circ} \mathrm{C}\right)$, air speed $U\left(20 \mathrm{~m} \mathrm{~s}^{-1}\right)$, liquid water content LWC $\left(0.5 \mathrm{~g} \mathrm{~m}^{-3}\right)$, and droplet diameter D $(15 \mu \mathrm{m})$.

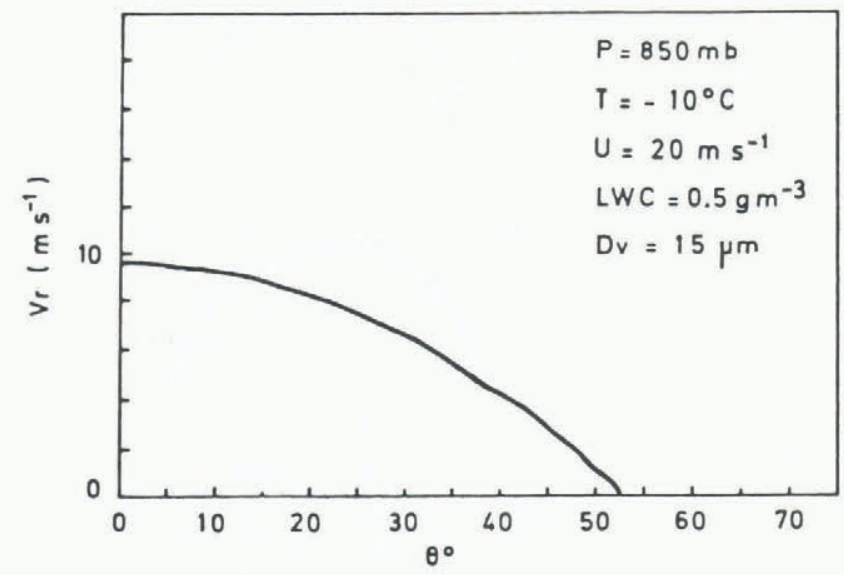

Fig.4. Local impact speed (radial component versus the angle of impact $\theta$ on the cylinder).

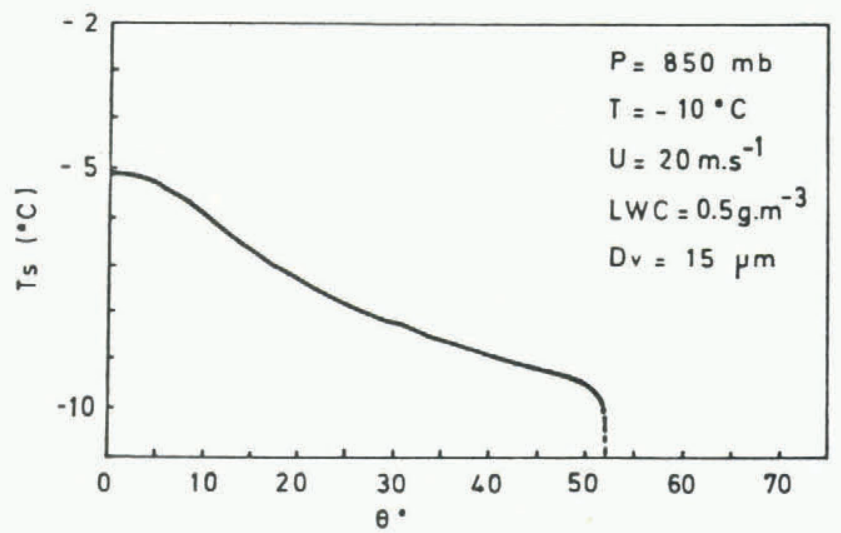

Fig.5. Local surface temperature versus the angle of impact $\Theta$ on the cylinder (from Lozowski and others 1979).

Under these conditions, $V_{r}$ decreases from $V_{0}=9.8 \mathrm{~m} \mathrm{~s}^{-1}$ to $V_{r}\left(\Theta_{M}\right)=$ zero, at the maximum impinging angle, which is $\theta_{M}=53^{\circ}$.

Figure 5 illustrates the variation of the surface temperature $T_{S}$ against the angle $\theta$, which is obtained from the model of Lozowski and others (1979). The parameters used are the same as in Figure 4 . The local surface temperature decreases from $\mathrm{T}_{\mathrm{S}}(0)=-5.2^{\circ} \mathrm{C}$ at the stagnation line to $\mathrm{T}_{S}\left(\theta_{M}\right)=-9.9^{\circ} \mathrm{C}$ at the maximum impinging angle. 4.3. Formulation of the ice density

To take into account the real droplet spectrum, we assume that the local ice density $\rho(\theta)$ is a mean value of the discrete densities induced by each of the droplet categories weighted by the liquid-water content of these droplets:

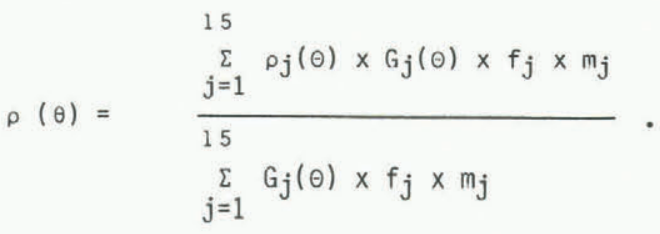

The index $\mathrm{j}$ characterizes the droplet diameter category, and ranges from 1 to 15 when the corresponding droplet diameter ranges from 3 to $45 \mu \mathrm{m}$, $\mathrm{Ii}_{\mathrm{j}}$ is the liquid water mass of a droplet of diameter $a_{j}, f_{j}$ is the fraction of the total concentration consisting of the $j^{\text {th }}$ size category, $G_{j}(\theta)$ is the local collection efficiency of droplets of diameter $d_{j}$, and $\rho_{j}(\theta)$ is the local density calculated for the $j$ th category impinging at the angle $\theta$.

It is assumed that freezing is an individual process for droplets and that droplets remain approximately spherical on freezing. This assumption is valid if the impact speed and the surface temperature are moderately low; under these conditions the ice density ranges from 100 to $700 \mathrm{~kg} \mathrm{~m}^{-3}$ (Macklin 1962). For high impact speed and surface temperatures near $0^{\circ} \mathrm{C}$, this assumption is no longer justified but the above formula is still valid because, for all droplet categories, the ice density reaches the maximum value of $917 \mathrm{~kg} \mathrm{~m}^{-3}$. 4.4. Result concerning the variation of the ice density with the angle

Figure 6 shows the variation of ice density against the angle on the cylinder, calculated when parameters are pressure $P$ ( 850 mbar), temperature $\mathrm{T}\left(-10^{\circ} \mathrm{C}\right)$, air speed $\mathrm{U}\left(20 \mathrm{~m} \mathrm{~s}^{-1}\right)$, and liquid water content LWC $\left(0.5 \mathrm{~g} \mathrm{~m}^{-3}\right)$. The cloud droplet spectrum is indicated in the upper right corner of the figure. The vertical scale is the frequency distribution of the concentration; each size category is $3 \mu \mathrm{m}$ wide and is plotted horizontally from 3 to $30 \mu \mathrm{m}$. The median volume diameter is $13 \mu \mathrm{m}$. Figure 6 shows 


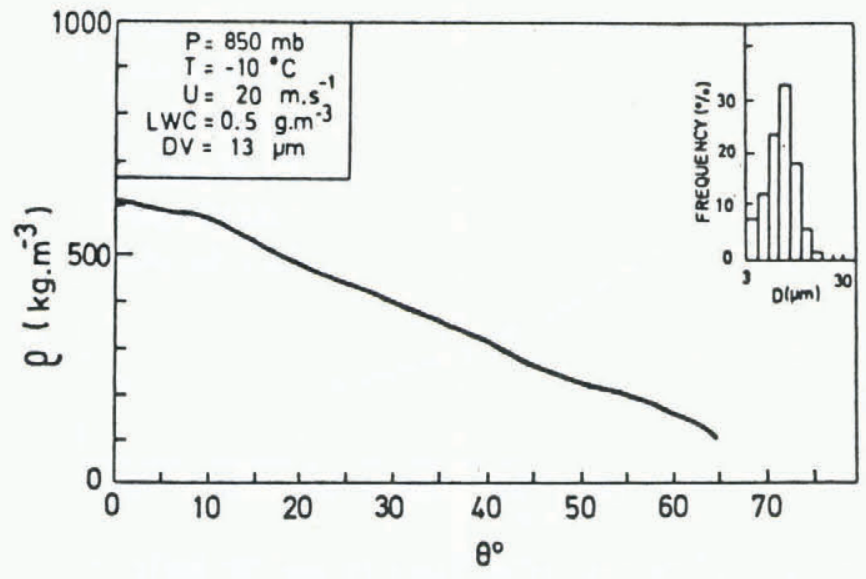

Fig.6. Ice density variation with the angle of impact $\theta$ on the cylinder and the corresponding input droplet spectrum.

that the ice density decreases from $605 \mathrm{~kg} \mathrm{~m}^{-3}$ at the stagnation line value, to $110 \mathrm{~kg} \mathrm{~m}^{-3}$ at the maximum impinging angle $\theta_{M}=65^{\circ}$.

\section{EFFECT OF THE DENSITY VARIATION ON THE PREDICTED} PROFILE

\subsection{Sensitivity to the droplet spectrum}

The variation of ice density depends on various parameters such as pressure, temperature, air speed, liquid water content, and droplet distribution. The role of each parameter has been studied, and we focus our attention in this paper on the influence of the droplet spectrum.

Figures 7 and 8 illustrate the results of simulations performed for various droplet spectra; the other parameters are identical with those of Figure 6 . Three spectra, (a), (b), and (c), are displayed in the upper right corner of Figure 7. The median volume diameters are 9,13 , and $23 \mu \mathrm{m}$, respectively. These values are representative of the range of spectra encountered during the measurements. The corresponding curves of the ice density variation are also labelled (a), (b), and (c).

The simulated profiles calculated for cases (a), (b), and (c) are represented by the thick lines in Figure 8 . The thin lines correspond to simulations with a fixed density $\left(890 \mathrm{~kg} \mathrm{~m}^{-3}\right)$, as proposed by Lozowski and others (1979). The most important difference between the two simulations concerns the thickness of the ice deposit. For (a), the calculated density is about three times smailer than the fixed density; then the thickness of ice is three times larger. The shape of the ice deposit changes from sharp-pointed for (a), to flat for (b), and to elliptical for (c), when the median volume diameter varies from 9,13 and $23 \mu \mathrm{m}$, respectively. This means that a flat deposit is observed for a specific droplet spectrum (median volume diameter equal to $13 \mu \mathrm{m}$ in this case), when the other parameters are fixed. From Figure 7 , the forecasted flat deposit

(b) is associated with a quasi-linear decrease of the ice density with the angle; by contrast, the curves (a) and (c) show a lower decrease than curve (b). 5.2. Comparison between the new predicted profiles and the observed profiles

Figures 9 and 10 display the variation of ice density with the angle and the predicted profiles, respectively, for the experimental measurements presented in Figure 1. Figure 9 indicates that the ice density decreases slowly from the stagnation line to the angle $\theta=55^{\circ}$, from 815 to $500 \mathrm{~kg} \mathrm{~m}^{-3}$ for case (a) and from 662 to $333 \mathrm{~kg} \mathrm{~m}^{-3}$ for case (b), respectively. Then the ice density decreases quickly to the values 185 and $113 \mathrm{~kg} \mathrm{~m}^{-3}$ for the angle $65^{\circ}$ (case (a)) and $60^{\circ}$ (case (b)), respectively.

Froin Figure 10, the simulated profiles obtained with a variable density are larger than those obtained with the constant density $\left(890 \mathrm{~kg} \mathrm{~m}^{-3}\right)$, but they still have an elliptical shape which was not observed during the experiment. We notice that the decrease of the ice density is not quasi-linear and that the most important density variations are in the sectors where the ice growth fluxes are the smallest. This result seems to indicate that the ice density variation cannot explain the differences between the shape of the observed ice deposit of (b) in Figure 1 and the predicted shape of (b) in Figure 7.

As suggested in section 3 , the ice density variation is not the only effect involved in the flattening and widening of a profile. In order to produce a realistic result, this effect has to be taken into account at the same time as a variation in the local collection efficiency due to the time evolution of the profile. In fact, these effects are

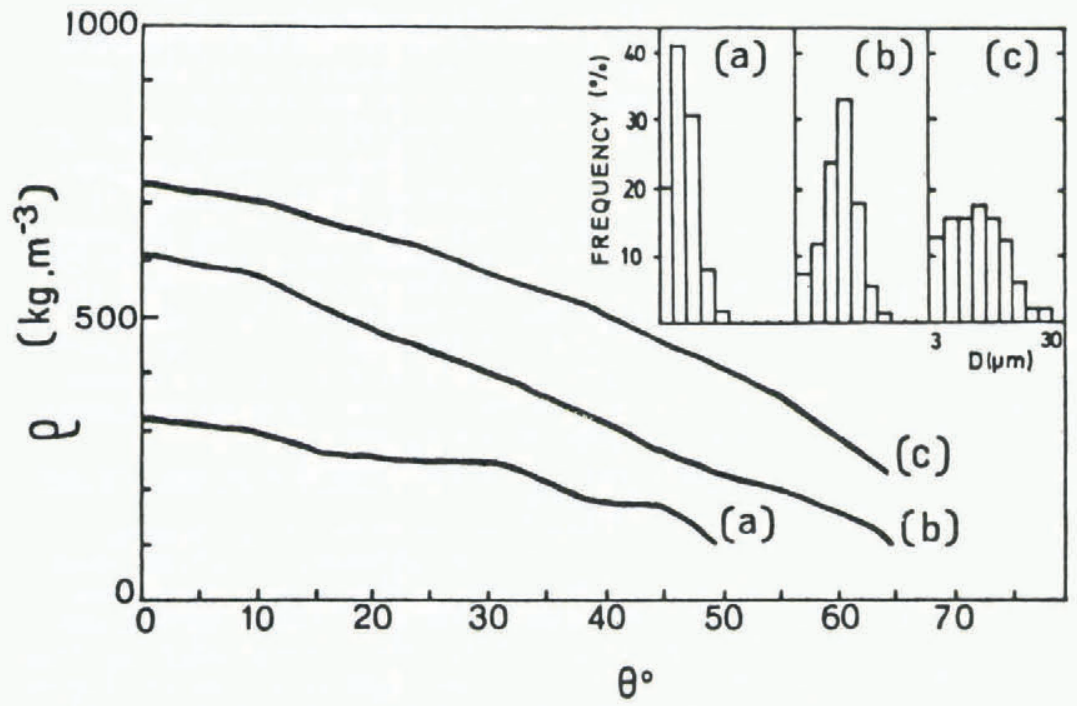

Fig.7. Ice density variations with the angle of impact on the cylinder for three cloud droplet spectra. Dther conditions identical to Figure 6 .

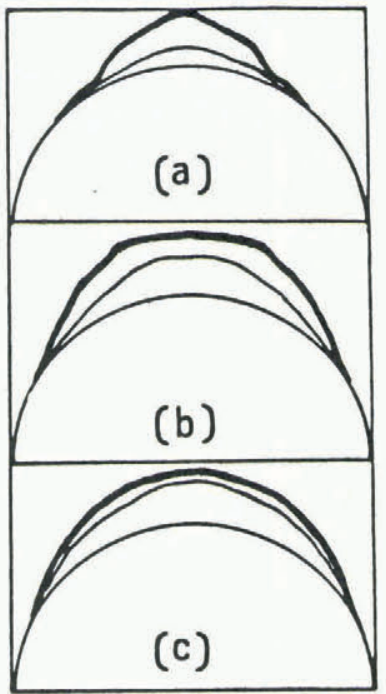

Fig.8. Simulated ice profiles for a duration $\Delta t=10 \mathrm{mn}$. Thick lines represent densities of Figure 7; thin lines represent fixed density. 


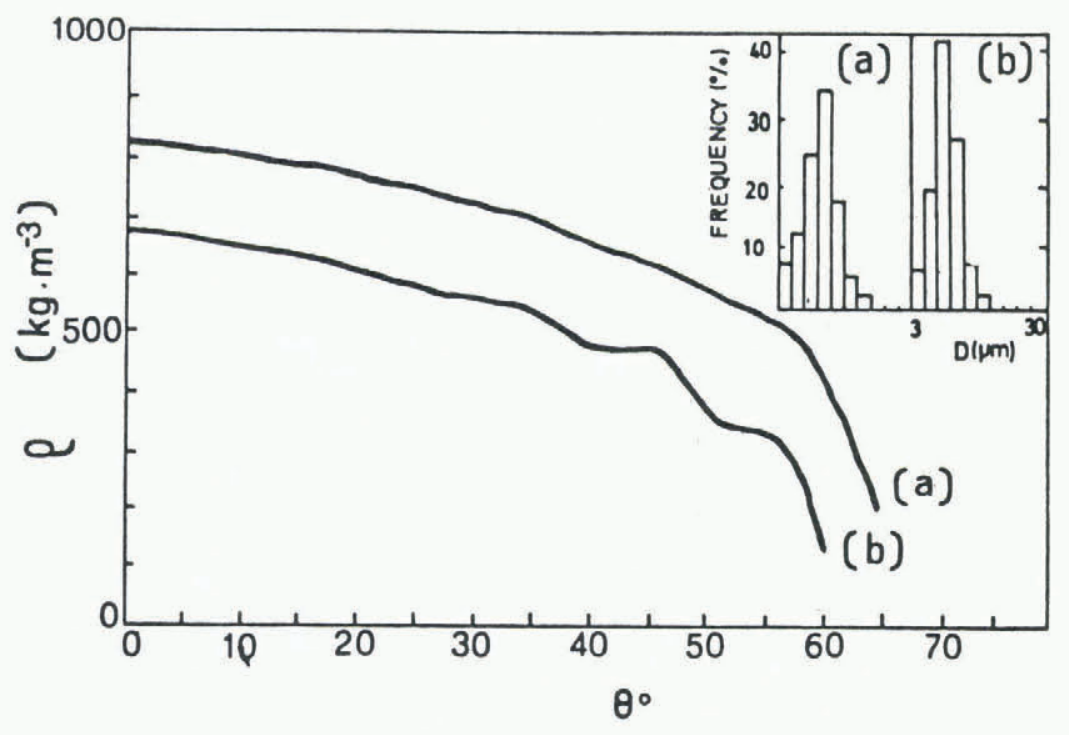

Fig.9. Ice density variations with the angle of impact on the cylinder calculated for curves (a) and (b) with the meteorological parameters described in (a) and (b) in Figure 1, respectively.

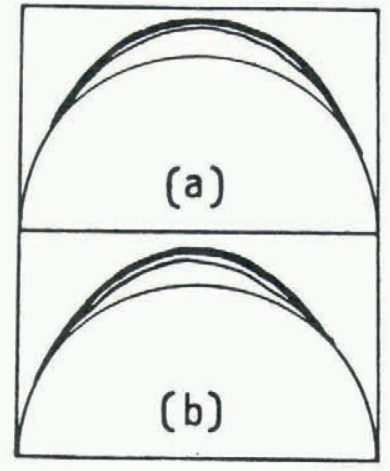

Fig.10. Simulated ice profile. Thick lines represent densities of Figure 9; thin lines represent fixed density. linked; a variation in the local collection efficiency $\mathrm{G}_{\mathrm{j}}(\theta)$ induces a local density variation (see Equation (2)) and changes the profile, inducing a new variation in the collection efficiency, and so on. Ackley and Templeton (1979) indicate a decrease of the total collection efficiency of small droplets impinging on an elliptical profile with the increase of the eccentricity. For any observed profile the calculations are more difficult than for the elliptical shape and have not yet been done. Moreover, it is difficult to guess the effect of this variation because the local collection efficiency $G_{j}(\theta)$ is involved, firstly, in the evaluation of the local ice density (directly in Equation (2) and also indirectly through the surface temperature $T_{s}(\theta)$ used to express $\left.\rho_{j}(\theta)\right)$ and, secondly, in the determination of the ice growth flux $R$ ( see Equation (1)) on which the plot of the ice profile depends. It must be pointed out that for the examples presented in Figures 9 and 10 the droplet spectra used in the simulation are the spectra measured by the PMS ASSP-100. Pinnick and others (1981) show that the droplet size measured by the probe is inaccurate for a diameter $<8 \mu \mathrm{m}$, this corresponds to the first three channels of the probe. The small error in the measured spectra may contribute to the difference between the observed and the simulated profiles.

\section{CONCLUSIONS}

Experiments on icing have been performed on rotating and fixed cylinders in a wind tunnel. Measurements of ice density on the rotating cylinder indicate a rather good agreement with Macklin's results (1962) and lead us to use his formulation of ice density as a function of $\left(-r V_{0} / T_{S}\right)$.

The profiles of the ice deposits on the fixed cylinder are compared to the results of simulations by using a model developed by Lozowski and others (1979). In order to improve this simulation, we have introduced the ice density variation as a function of the cylinder angle. This calculation is found to be very sensitive to the cloud droplet spectrum. In some cases this calculation leads to the simulation of a flat profile of the ice deposit, but in other cases this new formulation is not sufficient and it may be necessary to take the time evolution of the profile into account. Continuation of the work described in this paper is now under consideration.

\section{ACKNOWLEDGEMENTS}

The authors would like to express their appreciation to Professor Soulage for his guidance during the period of this study, to Professor Coulman for his comments on the manuscript, and to Dr Pointin for helpful discussions. They are indebted to Dr Ramond, Director of the Institut et Observatoire de Physique du Globe, Clermont-Ferrand, for allowing them to use the observatory at the summit of Puy de Dôme for their experiments. Thanks are due to the technical staff of the Laboratoire Associe de Météorologie Physique, Université de Clermont II.

The research was supported by the Direction des Recherches Etudes et Techniques under contract no. 81.34 .646 .

\section{REFERENCES}

Ackley S F, Templeton M K 1979 Computer modeling of atmospheric ice accretion. CRREL Report 79-4 Langmuir I, Blodgett K B 1960 Mathematical investigation of water droplet trajectories. In Suits C G (ed) Collected works of I Langmuir Vol 10. Oxford etc, Pergamon Press: 348-393 Lozowski E P, Stallabrass J R, Hearty P F 1979 The icing of an unheated non-rotating cylinder in liquid water droplet-ice crystal clouds. Canada. National Research Council. Division of Mechanical Engineering. Report LTR-LT-96

Macklin W C 1962 The density and structure of ice formed by accretion. Quarterly Jourmal of the Royal Meteorological Society 88(375): 30-50

Pinnick R G, Garvey D M, Duncan L D 1981 Calibration of Knollenberg FSSP light scattering counters for measurements of cloud droplets. Journal of Applied Meteorology 20: 1049-1057 